\title{
HEAT-INDUCED INKLESS ECO-PRINTING INSPIRED BY PAPER DISCOLORATION: A REVIEW
}

\author{
Peixing Wei \\ Southeast University \\ China \\ Wanyong Tuo \\ Anyang Institute of Technology \\ ChINA \\ Sheng He \\ China National Bamboo Research Center \\ China \\ Guohua Liu \\ Jiangsu Vocational College of Agriculture and Forestry \\ China \\ (Received October 20I9)
}

\begin{abstract}
In this paper, the art-of-the-state of heat-induced inkless eco-printing (HIEP) technology in recent years was summarized and prospected, mainly from the printing effect, degree of carbonization, environmental impact and feasibility. The main results were as following: (1) The paper used in HIEP is predominantly yellow in color, which enables a practical printing effect. (2) After HIEP, the paper exhibits no significant carbonized microstructure and keeps its high strength. (3) HIEP is an ecologically and environmentally preferable technology. Only a small amount of toxic products is generated, and no carcinogens are emitted. (4) No significant damage to the paper is evident following HIEP, as the degree of heat experienced during HIEP is far below that experienced during a thermogravimetric (TG) experiment. Additionally, the evaporated water has a buffering effect. Based on the previous research results, this paper finally pointed out the possible research direction in terms of discoloration mechanism and printing effect, environmental impact improvement, paper damage mechanism and strength during HIEP, high-temperature printing head installation and relevant techniques, optimization of printing process parameters.
\end{abstract}

KEYWORDS: Heat-induced inkless eco-printing (HIEP), carbonized microstructure, pyrolysis products, environmental impact. 


\section{INTRODUCTION}

The histories of paper-making and printing go back approximately two thousand and one thousand years, respectively (Wang 2017). These inventions have made invaluable contributions to the recording of human history, the dissemination of culture and the advancement of science and technology and have laid the groundwork for modern printing. Based on thousands of years of improvement and the computer's emergence in the mid-twentieth century in particular, the printer has developed rapidly. In the 1960s, commercial dot matrix (White et al. 1984) and laser printers (Boutopoulos et al. 2014) were created, followed by the first inkjet printer in the 1970s (Park et al. 2007) and, later, thermal printing (Kishimura et al. 2005) and 3D printing (Gill and Kaplas 2009). These printing technologies can print not only varied patterns but also many complicated real 3D objects (Gill and Kaplas 2009, Henke and Treml 2012, Xin et al. 2013, Wang and Liu 2014). The authors classify printing techniques into two main types of methods: methods based on bump technology, including stone carving techniques and $3 \mathrm{D}$ printing, and coloring methods, which rely on the distribution of dye (typically involving the application of a "paint color" to a "base material", e.g., word printing in ancient China, laser printing and inkjet printing). Laser and inkjet printers can release significant volumes of fine particles, heavy metals, benzene, formaldehyde, styrene, and other carcinogens in the form of gases during printing (Jensen and Rold-Petersen 1979, Gallardo 1994, Bar-Sela and Shoenfeld 2008, Theegarten et al. 2010, Morawska et al. 2009, Yoo et al., 2009, Saraga 2011, Wang et al. 2012, Gigac et al. 2015), and there is currently no effective recycling system for printing waste. The disposal of these wastes can damage the environment and harm human health. The recycling of paper is also adversely affected when the paper is colored by toner or ink (Chantigny et al. 2000).

Thus, in recent years, the printing industry has conducted extensive research on inkless or zero-ink (Zink) eco-printing technologies, with a focus on developing a new and distinct type of printing paper (Comiskey et al. 1998, Garai et al. 2016, Hays 2015, Sun et al. 2015). For example, ZINK Imaging Incorporation introduced a printing paper containing a significant amount of crystalline dye (Song and Wang 2010). Based on the color changes in this paper induced by the creation of dye in response to the application of heat during the printing process, ZINK developed the Pandigital inkless printer (Song and Wang 2010). In the water-spraying-based inkless printing process, the paper used for printing must be pretreated with special chemicals. Below $35^{\circ} \mathrm{C}$, the paper turns black upon contact with water. This black color vanishes after 22 hours, enabling this special paper to be reused (Sheng et al. 2015). Dell Incorporated introduced photographic printing based on the application of a special layer onto photo paper that can reflect light of different wavelengths and developed the Wasabi PZ310 mini-printer based on this technology. Other printing techniques have also been introduced that rely on inducing changes in the nanostructures of special materials on the surfaces of paper (Shestopalov et al. 2007, Choi and Park 2010, Shestopalov et al. 2010, Garai et al. 2016) or the use of liquid polymers (Yow and Routh 2006). All of the technologies mentioned above involve tailor-made printing paper. By contrast, Sun et al. (2009) proposed a new concept of inkless laser printing, whose mechanism was that paper color was changed instantaneously at ultra-high temperature. Additionally, laser carbonization printing (Yao and Zhao 2007) and the use of natural pigments (Rentschler 2005, El-Hennawi et al. 2012, Wataoka 2012) with ordinary printing paper represent different approaches to eco-printing technology. The severe carbonization induced in the printing region of the paper after laser carbonization printing and natural pigments can also be viewed as special inks, leading to the classification of these approaches as traditional coloring methods. 
Inspired by the yellowing discoloration of plant fibers (Carter 1996, Davidson 1996, Beyer et al. 2005, Fromageot et al. 2006, Wang et al. 2015), the radically new concept of heat-induced inkless eco-printing (HIEP) was proposed in 2010 (Chen et al. 2010, Chen et al. 2012), which obviates the need for ink during the printing process while achieving the same printing results using an ordinary sheet of office paper (Chen et al. 2012). This technology takes advantage of the tendency for paper to yellow, which is usually considered to be a disadvantage of printing paper. Although laser inkless printing (Sun et al. 2009) and heat-induced inkless printing achieved the same result, its damage of paper and environmental impact was not further studied. This paper reviews the research progress in HIEP (Chen et al. 2012, Chen et al. 2014a, Chen et al. 2014b, Chen et al. 2016), including the printing effect, degree of carbonization, environmental impact and feasibility (Wei et al. 2015, Chen et al. 2016a, Chen et al. 2016b), and then proposes potential research directions for HIEP.

\section{The definition and printing effect of HIEP}

HIEP is a type of printing that does not require any toner or ink. Using a special printer head composed of a high-temperature printing dot matrix or heat-inducing printing stylus to transfer heat, the required text or graphics can be formed on the paper via the yellowing and blackening caused by thermal or laser energy (Chen et al. 2012). Among traditional printing methods, thermal printing and rice paper pyrography also rely on this approach (Liu 1999). Thermal printing on dedicated thermal paper is based on a heat-induced chemical reaction and the coating of a compound onto the paper to cause a color change. Similarly, the rice paper used for pyrography must be sprayed or brushed in advance with a thin slurry composed of a variety of chemicals (Chen et al. 2014). Thus, both of these techniques involve the painting or writing of one or more colored materials (a coating) onto a base material of another color to form words or patterns. By contrast, HIEP requires only a single "base material" to achieve the effect of printing using the "coloring method".
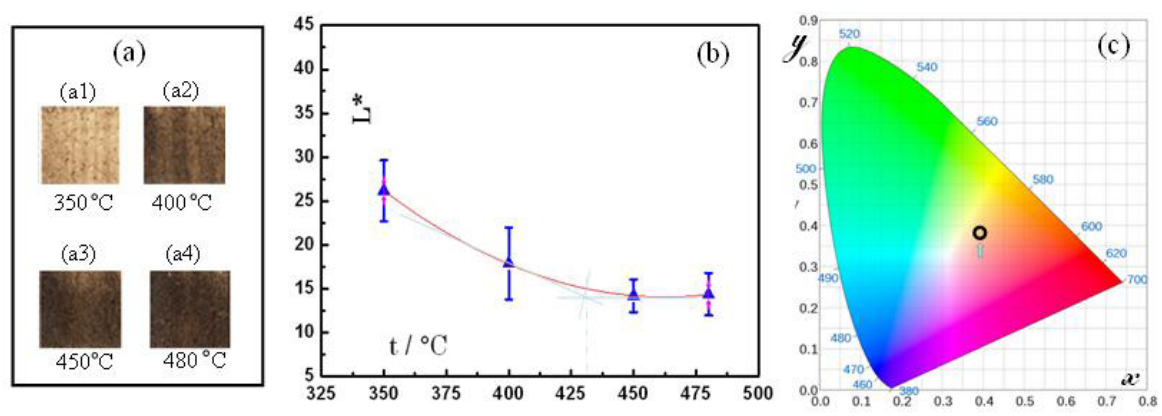

Fig. 1: Heat-induced blocks: (a) photographs of scan printing results, (b) corresponding lightness ( $\left.L^{*}\right)$, and (c) corresponding chromaticity $(x, y)$ (Chen et al. 2012).

The study of the printing effect of HIEP still remains at the stage of laboratory investigation through manual simulation. Heat-induced color blocks produced in such an investigation are shown in Fig. 1a.

Fig. 2a-d and Fig. 2e,f present the experimental results of simulated heat-induced printing by means of clicking and writing, respectively (Xie et al. 2014). The heat-induction temperature was above $500^{\circ} \mathrm{C}$ for the tests whose results are shown in Fig. 2c and Fig. 2d. 


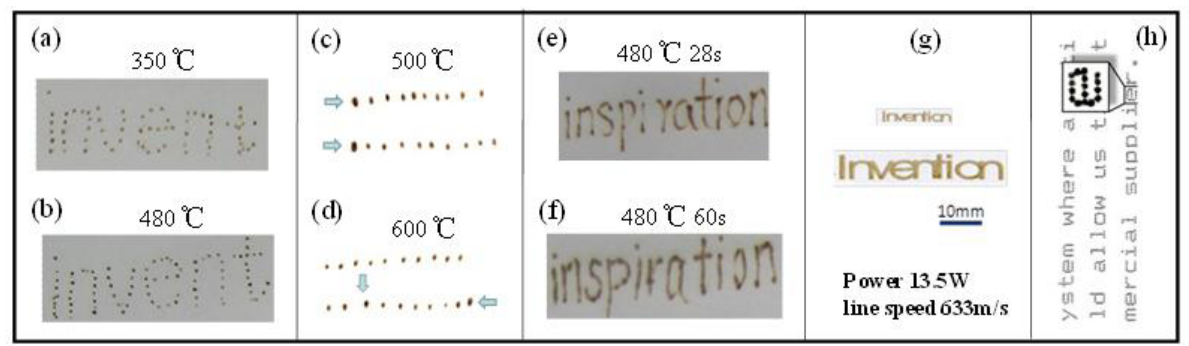

Fig. 2: HIEP simulated printing results (Chen et al. 2012, Xie et al. 2014): (a-d) the print-click method, (e, f) the scan method, (g) LIEP, and (b) dot matrix printing (1970).

From Fig. 2a-f, it is clear that although the heat-induced method has some disadvantages relative to the current state of the art in laser printing because of the current lack of research on the optimization of the printing technology parameters and the accurate control of the printing process, the text formed on the paper is clearly visible, and the printing effect of HIEP is similar to that of a dot matrix printer manufactured in the 1970s, as shown in Fig. $2 \mathrm{~g}$. For comparison, Fig. $2 \mathrm{~h}$ shows the results of simulated printing via laser inkless eco-printing (LIEP) using heat induction on normal A4 office paper (Chen et al. 2012). Although the characters formed by LIEP are yellow in color, heat-induction technology can achieve the desired level of discoloration for printing. Therefore, by bridging the gaps in chromaticity and lightness between HIEP and current printing through the optimization of the printing parameters and precise control of the printing process, HIEP can achieve a practical printing effect.

\section{Paper microstructure after HIEP and environmental impact}

HIEP does not require ink during the printing process and can achieve reliable printing results using an ordinary sheet of office paper. However, HIEP may damage the paper and may produce a small amount of harmful gases when the temperature is sufficiently high. Thus, the microstructure of the paper after HIEP and the categorization, quantification, and environmental assessment of volatiles require investigation and analysis to provide a scientific basis for the design of safe HIEP technology. The research progress on these topics is reviewed in this section.

\section{Carbonized paper microstructure after HIEP}

The first and second columns in Fig. 3 show sets of microstructure images obtained after simulated scan printing and click printing, respectively (Chen et al. 2014a, Chen et al. 2014b, Chen et al. 2016a,b). In the first column of Fig. 3, it is seen that slight scratches remained on the paper surface after scan printing (as indicated by a "w"). However, the basic characteristics of the paper were retained, namely, the large number of recesses and voids formed through the mutual superposition of fibers, whose main ingredients are cellulose and hemicelluloses (Nathan et al. 2005). Several particles or slightly larger lumps can also be observed in the images in Fig. 3, as indicated by the squares. Most of these substances are inorganics (filler or addition agents) added during the paper-making process, which are usually classified as "ash" (Ren et al. 2009). Very obvious concave indentations remained after click printing (as indicated by a " $u$ " in the second column of Fig. 3). The microstructures did not differ markedly depending on the heat-induction temperature used (Fig. 3a-d). 


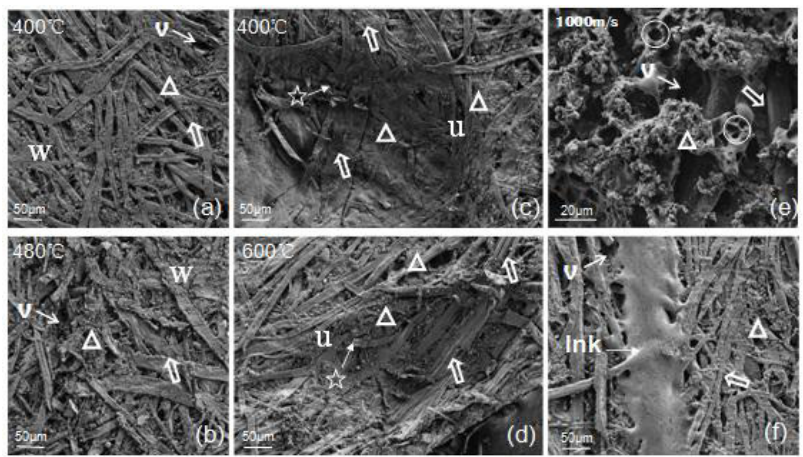

Fig. 3: Paper microstructures after various forms of printing (Chen et al. 2014a, Chen et al. 2014b, Chen et al. 2016a, Chen et al. 2016b): (a, b) scan printing, (c, d) click printing, (e) LIEP, and (f) state-ofthe-art laser printing.

The distinct features of HIEP can be appreciated from a comparison with the results of LIEP (Fig. 3e) and current laser printing technology (Fig. 3f) (Chen et al. 2014a). After LIEP, the fine structure looks like that of a microsludge material, with a texture similar to that of a softening substance generated by fiber carbonation decomposition, and a number of small holes (indicated by circles) and cauliflower core-like clots (indicated by triangles) can be clearly observed. In current laser printing (Fig. 3f), the paper surface adsorbs a large amount of ink powder. By contrast, the simulated HIEP samples, for both scan printing and click printing, showed no serious carbonization such as that seen with LIEP nor any residual ink powder such as that currently used in laser printing. Therefore, for paper recycling, the printing paper used for HIEP requires the removal of the least amount of colored material.

\section{Pyrolysis products and environmental impact of HIEP}

Fig. $4 \mathrm{a}$ and Fig. $4 \mathrm{~b}$ presents content area percentages of the main pyrolysis products in air at each temperature and the pyrolysis volatiles with an area content exceeding $2 \%$ at $250-700^{\circ} \mathrm{C}$ under an air atmosphere (Chen et al. 2014b). The products shown in the figure are those that represent more than $2 \%$ of the area in the mass spectral analysis; the $\mathrm{Y}$ coordinate is the area percentage. And the numbers represented different pyrolysis products: 1- $\mathrm{CO}_{2}, 2-\mathrm{C}_{2} \mathrm{H}_{4} \mathrm{O}, 3-\mathrm{C}_{3} \mathrm{H}_{6} \mathrm{O}$, 4- $\mathrm{C}_{2} \mathrm{H}_{4} \mathrm{O}_{2}, 5-\mathrm{C}_{3} \mathrm{H}_{4} \mathrm{O}_{2}, 6-\mathrm{C}_{5} \mathrm{H}_{10}$ (cis-2-Pentene), 7- $\mathrm{C}_{5} \mathrm{H}_{10}$ (Trans-2-Pentene), 8- $\mathrm{C}_{3} \mathrm{H}_{4} \mathrm{O}_{2}$, 9- $\mathrm{CH}_{2} \mathrm{Cl}_{2}, 10-\mathrm{C}_{5} \mathrm{H}_{10} \mathrm{O}, 11-\mathrm{C}_{2} \mathrm{H}_{14} \mathrm{~N}_{2}, 12-\mathrm{C}_{5} \mathrm{H}_{4} \mathrm{O}_{2}, 13-\mathrm{C}_{5} \mathrm{H}_{6} \mathrm{O}_{2}, 14-\mathrm{C}_{4} \mathrm{H}_{6} \mathrm{O}_{3}, 15-\mathrm{C}_{6} \mathrm{H}_{6} \mathrm{O}_{3}$, 16- $\mathrm{C}_{7} \mathrm{H}_{5} \mathrm{NS}, 17-\mathrm{C}_{8} \mathrm{H}_{8} \mathrm{O}_{3}, 18-\mathrm{C}_{10} \mathrm{H}_{10} \mathrm{O}_{3}, 19-\mathrm{C}_{6} \mathrm{H}_{12} \mathrm{O}_{6}, 20-\mathrm{C}_{9} \mathrm{H}_{10} \mathrm{O}_{4}$, and $21-\mathrm{C}_{16} \mathrm{H}_{22} \mathrm{O}_{4}$.

The volatiles are divided into six classes according to their harmful effects: Class I includes only $\mathrm{CO}_{2}$; Classes II and III include irritants and flammable products, respectively (Fig. 5a); Class IV includes corrosive products; and Classes V and VI include moderately and highly toxic products, respectively. According to Fig. 5, the pyrolysis volatiles do not include any carcinogens. For Class I, 1- $\mathrm{CO}_{2}$ is the most common product, followed by the lightly polluting Class II and III products, which include a number of different volatiles. The main toxic products included in Classes V-VI are 2- $\mathrm{C}_{2} \mathrm{H}_{4} \mathrm{O}, 3-\mathrm{C}_{3} \mathrm{H}_{6} \mathrm{O}, 5-\mathrm{C}_{3} \mathrm{H}_{4} \mathrm{O}_{2}, 9-\mathrm{CH}_{2} \mathrm{Cl}_{2}, 12-\mathrm{C}_{5} \mathrm{H}_{4} \mathrm{O}_{2}, 13-\mathrm{C}_{5} \mathrm{H}_{6} \mathrm{O}_{2}$, 16- $\mathrm{C}_{7} \mathrm{H}_{5} \mathrm{NS}$, and $21-\mathrm{C}_{16} \mathrm{H}_{22} \mathrm{O}_{4}$ (Fig. 5b). In general, two types of products in Classes $\mathrm{V}$ and VI are produced at each temperature (Fig. $5 \mathrm{a}$ ). 

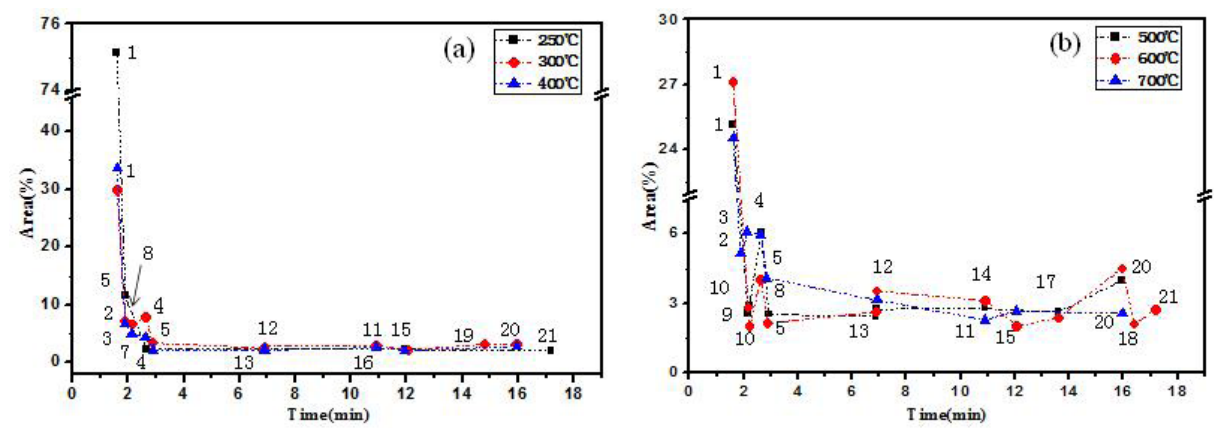

Fig. 4: The main pyrolysis products of the HIEP paper printing process at (a) $250-400^{\circ} \mathrm{C}$ and (b) $500-700^{\circ} \mathrm{C}$.

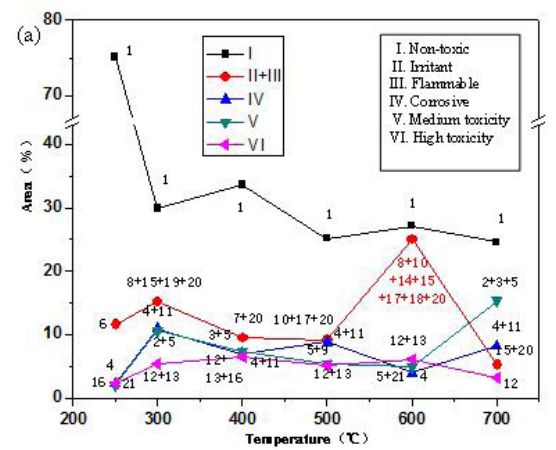

Fig. 5: The content area percentages of main pyrolysis products in air generated at various temperatures, representing the environmental impact of the printing process.

Generally speaking, $\mathrm{CO}_{2}$ (Class I) and lightly polluting products (Classes II and III) account for a significant amount of the volatiles observed. The sum of Classes I-III is approximately $50 \%$. The proportion of each class of toxic products (Classes V and VI) is approximately 5\% at most temperatures (Fig. 5a). In current laser printing technology, the paper surface adsorbs a substantial amount of ink powder (Fig. 3f); by comparison, HIEP leaves only a number of concave indentations and recesses on the paper's surface and does not generate a significant amount of pyrolysis volatiles. HIEP also significantly reduces the waste paper recycling costs associated with ink processing, and its use therefore provides excellent economic and environmental benefits.

\section{Nondestructive printing mechanism of HIEP}

Although it is well known that paper cannot withstand fire, it has been shown that no damage is evident after HIEP for a heat-induction temperature of $600^{\circ} \mathrm{C}$. Based on an analysis of the thermal and physical properties and the printing contact time, the feasibility of the precise control of HIEP for industrial applications has been validated (Xie et al. 2014). Fig. 6 presents the TG thermal physical properties of the paper (Xie et al. 2014). The TG curves can be separated into six stages (Fig. 6a) below $600^{\circ} \mathrm{C}$. 

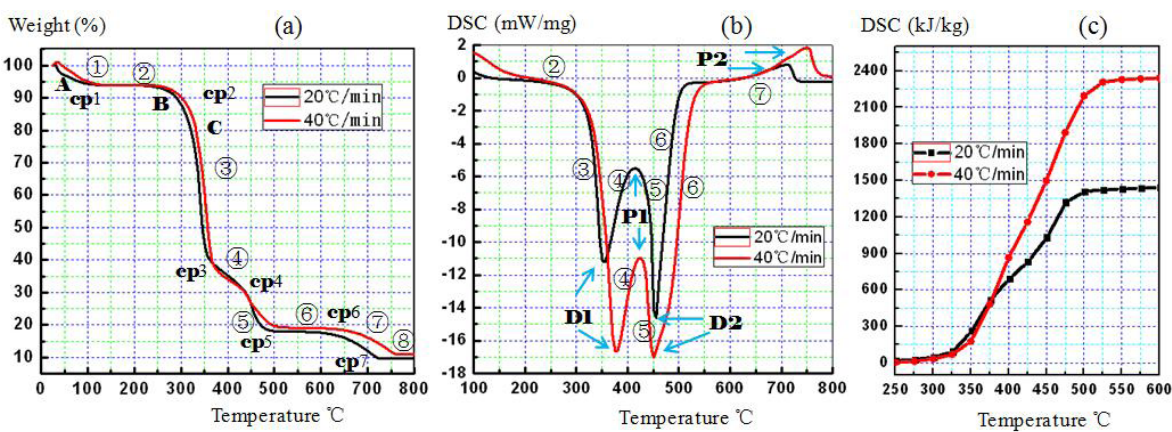

Fig. 6: Thermal analysis of the paper (Xie et al. 2014): (a) TG curves, (b) DSC curves, and (c) endothermic curves.

The pyrolysis of the paper predominantly occurs during the third to fifth stages of the TG curves (Fig. 6a). The differential scanning calorimetry (DSC) curve (Fig. 6b) features two endothermic peaks (D1 and D2) and one exothermic peak (P1). The locations of these peaks depend on the heating rate. The temperatures of the critical points increase with an increasing heating rate (Fig. 6). According to Li et al. (2005) and Wang et al. (2009) who investigated the TG behavior of wood and biomass in air, these two endothermic peaks (Fig. 6b, D1 and D2) primarily arise from the pyrolysis of hemicelluloses and cellulose. The exothermic peak P1 forms for two reasons. First, the material burns at a high temperature (referred to as "secondary combustion"), releasing the heat generated in the third stage of weight loss (Wang et al. 2009, Tan et al. 2006). Second, a transitional stage in the TG curve can be observed (see Fig. 6a), because hemicellulose pyrolysis and cellulose pyrolysis occur at different temperatures. The total thermal solution in this stage absorbs less than the required amount of heat, which contributes to the formation of the exothermic peak. Overall, the pyrolysis process is endothermic, as the endothermic contribution exceeds the exothermic contribution (Fig. 6c).

According to Fig. 6a, the paper experiences significant weight loss when the temperature reaches approximately $350^{\circ} \mathrm{C}$. During HIEP, why does the paper not incur serious damage when the temperature exceeds $600^{\circ} \mathrm{C}$ ? The reason, according to the author, is that the vaporization of the moisture in the paper (greater than 5\%) serves as a buffer, and furthermore, the heating time is very short: in the experiment presented in Fig. 6, even at a high heating rate of $40^{\circ} \mathrm{C} \cdot \mathrm{min}^{-1}$, the time required to heat the paper from $300^{\circ} \mathrm{C}$ to $400^{\circ} \mathrm{C}$ was $150 \mathrm{~s}$, whereas during the simulated HIEP process, the time required to print each dot at $450^{\circ} \mathrm{C}$ was approximately $30 \mathrm{~ms}$. In other words, the degree of heat transfer differed between the HIEP and TG experiments by at least 2-3 orders of magnitude (Xie et al. 2014).

\section{Feasibility of HIEP}

As seen from the effect of the heating rate on the weight loss (pyrolysis) of the paper (Fig. 6), heating paper at a lower heating rate requires a longer heating time to reach a given temperature and thus leads to greater weight loss (Fig. 6a) and less heat absorption (Fig. 6c). Although pyrolysis requires much more heat at a higher heating rate, such rapid heating can significantly shorten the time needed to reach a specific temperature. In addition, rapid heating can reduce the weight loss of the paper, which is desirable for the manufacturability and commercialization of the HIEP process (Xie et al. 2014). In other words, it is clear that the paper loses weight quickly 
between 400 and $600^{\circ} \mathrm{C}$. The paper weight-loss rate can be closely controlled by monitoring the heat-induction temperature and time. These findings provide a scientific basis for controlling the weight loss of paper during yellowing and discoloration and for preventing damage based on the TG behavior of the paper (Xie et al. 2014).

However, if the heat-induction temperature is excessively high, the requirements concerning the material of the print head, printer security and other HIEP parameters are also high. Temperatures ranging between 400 and $600^{\circ} \mathrm{C}$ are reasonable for heat-induced printing. As mentioned above, HIEP can achieve a practical printing effect within a sufficiently short time interval to maintain the strength of the paper and avoid any obvious carbonation. In summary, HIEP, a new inkless eco-printing technology, has been shown to be viable.

Moreover, the environmental impacts of the pyrolysis volatiles produced from newsprint and silk have also been analyzed (Wei et al. 2015). At HIEP temperatures $\left(400-600^{\circ} \mathrm{C}\right.$ ), the toxicity of the pyrolysis volatiles in the printing paper was found to be the lowest, with the best environmental friendliness, whereas the impact of newspaper is the worst and that of silk is in the middle.

The printing effect on all three kinds of materials was expected to be desirable (Wei et al. 2015). However, the color could be clearly observed through the back of the newsprint because of its higher permeability. Of the three materials, printing paper was found to be the most suitable for HIEP, and newsprint, the least suitable. Silk may still be used in HIEP for the production of art, name cards and clothing nameplates in small amounts (Wei et al. 2015).

\section{Potential research directions}

Over the past five years, the printing effect, environmental impact, and damage mechanism of HIEP and the suitability of printing materials for HIEP have been studied and some progress has been achieved. However, further investigations are needed to improve this new technology. To this end, a greater understanding of the pyrolysis of biomass (considering the relevant biological, heat transfer, and chemical aspects) and color science will be required. Meanwhile, cross-disciplinary research including laser technology (for instance, LIEP), nanoscience (with regard to nano-level pyrolytic carbonization on the paper surface), photochemistry (with regard to the behavior of chromophores in photo-oxidization and photodegradation), paper-manufacturing science (including information regarding biomass hydrolysis, enzyme treatment, graft changes and other chemical treatments to make paper more suitable for HIEP), high-temperature materials science, and mechanical and transmission-related developments (because the printer heads will require sophisticated transmission and electronic control) will be essential for solving the next generation of research problems.

\section{Discoloration mechanism and printing effect}

As mentioned above, the printing effect of HIEP is similar to that of an early dot matrix printer. Although the yellowing discoloration of paper is a well-known phenomenon, the mechanism that drives it is not yet clear. Moreover, HIEP is performed under high-temperature and short-duration conditions. According to chemical theory, therefore, the relevant discoloration mechanisms should be different. According to preliminary observations, no obvious carbonization occurs during HIEP; thus, the discoloration of HIEP is not caused by paper carbonization. Because the tendency for paper to yellow at room temperature is generally considered to be a disadvantage, researchers have tended to focus on the elimination of the yellow coloration. However, discoloration is an essential component of the HIEP process. Thus, the mechanism of paper discoloration and the identification of the post-pyrolysis color groups need to be studied in depth. 
As a new technology, HIEP should offer adequate resolution, color-fastness and opacity. The resolution of HIEP should be similar to that of current inkjet (Stankovska et al. 2014) and thermal printing. Early samples produced using the manual simulated printing processes have been preserved for more than 4 years. Their color-fastness and opacity can visually meet the requirements of practical applications, but quantitative research on these samples has not yet been performed.

\section{Environmental impact}

Although the environmentally friendly qualities of HIEP have been preliminarily studied, this process might release a small quantity of harmful gases. The volatiles emitted from paper during 1s of high-temperature pyrolysis have been determined in a previous study. In HIEP, the use of a shorter heat-induction time should result in less pyrolysis, making this technique more environmentally friendly. In addition, the chemical compositions of paper differ by mill, and the heat transfer of HIEP is different from that in a paper pyrolysis experiment. Thus, comprehensive studies on HIEP's environmental impact should be conducted.

\section{Paper damage mechanism and strength during HIEP}

No significant damage to the paper was evident following HIEP, as the degree of heat experienced during HIEP is low and the evaporating water has a buffering effect. No serious carbonization was observed during a simulated HIEP experiment, even when the temperature reached $600^{\circ} \mathrm{C}$. If the duration of contact between the printing head and the paper were to be too long, however, the paper could certainly be burnt. Thus, the relationships between the process parameters, such as heat-induction temperature and contact time, and paper quality parameters, such as carbonization degree and strength, need to be determined. To achieve this goal, an unsteady heat transfer analysis (electronic simulation) could be conducted along the longitudinal and lateral directions of the paper with the development of a three-dimensional model.

\section{High-temperature printing head installation and relevant techniques}

By drawing lessons from the control systems for the current inkjet and thermal printing methods and using new manufacturing methods, the patterning and precision of HIEP can be improved. However, several new questions related to high-temperature operation may follow, such as those related to machine cooling, device complexity, stability and energy consumption. Although these problems can be solved using modern technologies, the final results will require quantitative analysis and experimental validation.

\section{Optimization of process parameters}

The process parameters, such as heat-induction temperature, printing speed, and printinghead pressure on the printing paper, need to be optimized both in general and for specific printing materials, such as silk.

In addition to the problems discussed above, the printing color of HIEP is dull compared with what can be achieved in current laser printing, which should also be addressed. Further studies on HIEP will pursue the research directions described above, and relevant findings will be reported in turn. 


\section{CONCLUSIONS}

HIEP is capable of achieving the same results as traditional printing using only a single "base material" (i.e., paper). Issues that arise during the life cycle of printed products, such as environmental pollution and human health risks caused by toner or ink and the challenges involved in the recycling and reuse of waste paper, are obviated by this process. The development of this printing method also constitutes a cross-study platform involving the fields of biology, photochemistry, nanoscience, paper-manufacturing science and color science. Thus, the development of HIEP represents a significant technological improvement and could be a landmark technology in the current era of worsening environmental pollution.

\section{ACKNOWLEDGEMENTS}

This work is financially by Jiangsu Planned Projects for Postdoctoral Research Funds (2018K121C), Enterprise Practical Training Program for Young Teachers in Higher Vocational Colleges of Jiangsu province (2019QYSJ071) and Qing Lan Project of Jiangsu Province.

\section{REFERENCES}

1. Beyer, M., Koch, H., Fischer, K., 2005: Role of hemicelluloses in the formation of chromophores during heat treatment of bleached chemical pulps. Macromolecular Symposia 232(1): 98-106.

2. Bar-Sela, S., Shoenfeld, Y., 2008: Photocopy machines and occupational antiphospholipid syndrome. Israel Medical Association Journal 10(1): 52-54.

3. Boutopoulos, C., Kalpyris, I., Serpetzoglou, E., Zergioti, I., 2014: Laser-induced forward transfer of silver nanoparticle ink: time-resolved imaging of the jetting dynamics and correlation with the printing quality. Microfluidics and Nanofluidics 16: 493-500.

4. Carter, H.A., 1996: The chemistry of paper preservation: Part 2. The yellowing of paper and conservation bleaching. Journal of Chemical Education 73(12): 1068-1073.

5. Comiskey, B., Albert. J.D., Yoshizawa, H., Jacobson, J., 1998: An electrophoretic ink for all-printed reflective electronic displays. Nature 394: 253-255.

6. Chantigny, M.H., Angers, D.A., Beauchamp, C.J., 2000: Decomposition of de-inking paper sludge in agricultural soils as characterized by carbohydrate analysis. Soil Biology and Biochemistry 32: 1561-1570.

7. Chen. J.X., Xie, J., Chen, F., 2010: A heat-inducing eco-printing method and print head device. China Patent 201010218623.8-ZL.

8. Chen, J.X., Wang, Y., Xie, J., Meng, C., Wu, G., Zu, Q., 2012: Concept of heat-induced inkless eco-printing. Carbohydrate Polymers 89(3): 849-853.

9. Chen, J.X., Xie, J., Pan, L., Wang, X., Xu, L.N., Lu, Y., 2014a: The microstructure of paper after heat-induced inkless eco-printing and its features. Journal of Wood Chemistry and Technology 34(3): 202-210.

10. Chen, J.X., Pan, L., Xie, J., Wu, G., Ren, H., Wang, Y., 2014b: Pyrolysis volatiles and environmental impacts of printing paper in air. Cellulose 21: 2871-2878.

11. Chen, J.X., Meng, C., Xie, J., Lan, L., Zhou, D., Chen, J.N., 2016a: Laser eco-printing technology for silk fabric patterns. Indian Journal of Fibre and Textile Research 41: 78-83. 
12. Chen, J.X., Xu, L., Xie, J., Wang, Y., Zu, Q. 2016b: The effect of laser inkless eco-printing on the carbonized microstructure of paper. Cellulose Chemistry Technology 50(1): 101-108.

13. Choi, S.J., Park, J.Y., 2010: High-aspect-ratio imageable top-surface lithography using UV-assisted inkless contact printing. Small 6(3): 371-375.

14. Davidson, R.S., 1996: The photodegradation of some naturally occurring polymers. Journal of Photochemistry and Photobiology B: Biology 33(1): 3-25

15. El-Hennawi, H., Ahmed, K., E1-Thalouth, I., 2012: A novel bio-technique using laccase enzyme in textile printing to fix natural dyes. Indian Journal of Fibre and Textile Research 37(3): 245-249.

16. Fromageot, D., Pichon, N., Peyron, O., Lemaire, J., 2006: Thermal yellowing sensitised by pre-photo-oxidation of non-deacidified paper. Polymer Degradation and Stability 91(2): 347-357.

17. Gallardo, M., 1994: Siderosilicosis due to photocopier toner dust. Lancet 344: 412-413.

18. Gill, S.S., Kaplas, M., 2009: Comparative study of 3D printing technologies for rapid casting of aluminum alloy. Materials and Manufacturing Processes 24(12): 1405-1411.

19. Gigac, J., Stankovska, M., Fiserova, M., Opalena, E., 2015: Improvement of inkjet print quality via hydrophilic polymers and base. Wood Research 60(5): 739-746.

20. Garai, B., Mallick, A., Banerjee, R., 2016: Photochromic metal-organic frameworks for inkless and erasable printing. Chemical Science 7(3): 2195-2200.

21. Hays, D.A., 2015: Paper documents via the electrostatic control of particles. Journal of Electrostatics 51: 57-63.

22. Henke, K., Treml, S., 2012: Wood based bulk material in 3D printing processes for applications in construction. European Journal of Wood and Wood Products 71: 139-141.

23. Jensen, M., Rold-Petersen, J., 1979: Itching erythema among post office workers caused by a photocopying machine with wet toner. Contact Dermatitis 5(6): 389-391.

24. Kishimura, A., Yamashita, T., Yamaguchi, K., Aida, T., 2005: Rewritable phosphorescent paper by the control of competing kinetic and thermodynamic self-assembling events. Nature Materials 4(7): 546-549

25. Li, A.M., Sun, L.J., Li, R.D., Wang, L., 2005: Characteristics of combustion and pyrolysis for decorative woods in poor-oxygen atmosphere. Journal of Engineering Physics and Thermophysics 26: 237-240.

26. Liu, Z.W., 1999: One method for rice paper pyrography. China Patent 99122434.5-CN.

27. Lou, Q., Qu, S., Jing, P., Ji, W.Y., Cao, J.S., Zhang, H., Liu, L., Zhao, J.L., Shen, D.Z., 2015: Water-triggered luminescent "nano-bombs" based on supra - (carbon nanodots). Advanced Materials 27: 1389-1394.

28. Morawska, L., He, C., Johnson, G., Jayaratne, R., Salthammer, T., Wang, H., Uhde, E., Bostrom, T., Modini, R., Ayoko, G., McGarry, P., Wensing, M., 2009: An investigation into the characteristics and formation mechanisms of particles originating from the operation of laser printers. Environmental Science and Technology 43(4): 1015-1022.

29. Mosier, N., Wyman, C., Dale B., Elander, R., Lee, Y.Y., Holtzapple, M., Ladisch, M., 2005: Features of promising technologies for pretreatment of lignocellulosic biomass. Bioresource Technology 96(6): 673-686.

30. Park, J.U., Hardy, M., Kang, S.J., Barton, K., Adair, K., Mukhopadhyay, D., Lee, C.Y., Strano, M., Alleyne, A., Georgiadis, J., Ferreira, P., Rogers, J., 2007: High-resolution electrohydrodynamic jet printing. Nature Materials 6(10): 782-789.

31. Ren, P.X., Jiang, J.C., Yang, X.S., Liu, J.L., 2009: Research progress on production of ethanol as fuel from fast pyrolysis products of lignocellulose. Biomass Chemical Engineering 43: 47-51. 
32. Rentschler, T., 2005: New approaches in papermaking with small particles. Wochenblatt für Papierfabrikation 133: 1385-1393.

33. Song, X., Wang, S., 2010: Simple analysis about inkless printing technology. Publishing and Printing 3:74.

34. Shestopalov, A.A., Clark, R.L., Toone, E.J., 2007: Inkless microcontact printing on selfassembled monolayers of fmoc-protected aminothiols. Journal of the American Chemical Society 129(45): 13818-13819.

35. Sun, X.L., Zhao, Z., Bai, Z., 2009: A new no ink laser printing technology. Mechatronics 15: 84-86.

36. Shestopalov, A.A., Clark, R.L., Toone, E.J., 2010: Catalytic microcontact printing on chemically functionalized h-terminated silicon. Langmuir 26(3): 1449-1451.

37. Saraga, D., Pateraki, S., Papadopoulos, A., Vasilakos, Ch., Maggos, Th., 2011: Studying the indoor air quality in three non-residential environments of different use: A museum, a printery industry and an office. Building and Environment 46: 2333-2341.

38. Stankovska, M., Gigac, J., Letko, M., Opalena, E., 2014: The effect of surface sizing on paper wettability and on properties of inkjet prints. Wood Research 59(1): 67-76.

39. Sun, H., Gao, N., Ren, J., Qu, X., 2015: Polyoxometalate-based rewritable paper. Chemistry of Materials 27(22): 7573-7576.

40. Sheng, L., Li, M.J, Zhu, S.Y, Li, H., 2015: Hydrochromic molecular switches for water-jet rewritable paper. Nature Communications 5: 55-55.

41. Tan, H., Wang, S.R., Luo, Z.Y., Cen, K.F., 2006: Pyrolysis behavior of cellulose, xylan and lignin. Journal of Fuel Chemistry Technology 34(1): 61-65.

42. Theegarten, D., Boukercha, S., Philippou, S., Anhenn, O., 2010: Submesothelial deposition of carbon nanoparticles after toner exposition: Case report. Diagnostic Pathology 5: 77-81.

43. White, C.W., Brussell, E.M., Williams, T.T., Eog, S.J., 1984: Gray-scale graphics using dot matrix printers. Behavior Research Methods Instruments and Computers 16: 273-276.

44. Wang, G., Li, W., Xue, Q.Z, 2009: Thermogravimetric behaviors of biomass' chemical components under air or syngas. Journal of Fuel Chemistry Technology 37(2): 170-176.

45. Wang, H., He, C.R, Morawska, L., 2012: Ozone-initiated particle formation, particle aging, and precursors in a laser printer. Environmental Science and Technology 46(2): 704-712.

46. Wataoka, I., 2012: Ink-jet printing using natural dyes. Journal of the Society of Fiber Science and Technology 68(6): 176-179.

47. Wang, L., Liu. J., 2014: Liquid phase 3D printing for quickly manufacturing conductive metal objects with low melting point alloy ink. Science China Technological Sciences 57: 1721-1728.

48. Wang, N., Tahmasebi, A., Yu, J., Huang, F., Mamaeva, A., 2015: A comparative study of microwave-induced pyrolysis of lignocellulosic and algal biomass. Bioresource Technology 190: 89-96.

49. Wei, P., Zhou, M., Pan, L., Wei, P., Zhou, M., Pan, L., Xie, J., Chen, J., Wang,Y.: Suitability of printing materials for heat-induced inkless eco-printing. Journal of Wood Chemistry and Technology 36(2): 129-139.

50. Wang, Q. 2017: The formation of "four great inventions" in ancient China and other issues. Studies in Dialectics of Nature 8: 72-77.

51. Xin, Z.Q Wang, S., Li, F.Y., Zhang, X.Y., Zhang, Z.L., Song, Y.L., 2013: The preparation of nanoparticles and their applications in ink-jetting and printing fields. Scientia Sinica (Chimica) 43: 677-686. 
52. Xie, J., Chen, J.X, Wang, Y., Liu, Y.F., Noori, M., Pan, L., 2014: Weight loss phenomenon of paper and the mechanism for negligible damage of heat-induced inkless eco-printing. Cellulose Chemistry and Technology 48(5-6): 577-584.

53. Yow, H.N., Routh, A.F., 2006: Formation of liquid core-polymer shell microcapsules. Soft Matter 2: 940-949.

54. Yao, N.M., Zhao, X.L., 2007: Printing paper carbonization method with laser high temperature. China Patent 200710071837.5-ZL.

55. Yoo, S., Hsieh, J.S., Zou, P., Kokoszka, J., 2009: Utilization of calcium carbonate particles from eggshell waste as coating pigments for ink-jet printing paper. Bioresource Technology 100: 6416-6421.

\author{
Peixing Wei* \\ Southeast University \\ School of Civil Engineering \\ NANJing, 2 IOog6 \\ P. R. CHINA
}

*Corresponding author: wayne0448123@163.com

\author{
Wanyong TuO* \\ Anyang Institute of Technology \\ School of Civil \& Architectural Engineering \\ ANYANG, 455000 \\ P. R. ChINA \\ *Corresponding author: twy2014@163.com
}

Sheng He

China National Bamboo Research Center

Hangzhou, 3 IOOI2

P. R. CHINA

Guohua Liu

Jiangsu Vocational College of Agriculture and Forestry

JuRONG, 2 I 2400

P. R. ChinA 
